Helena Buescu

Universidade de Lisboa - CEC

\title{
Colidir na História
}

\section{Resumo:}

A obra de Maria Velho da Costa dá-nos uma visão, aproximada pelas figurações das personagens e pelas complexas teias entre elas elaboradas, de um percurso histórico que dispensa qualquer forma de tranquilidade ou sossego. O desassossego que a habita não é apenas subjectivamente pessoal - sendo-o, também reflecte os sobressaltos vários que a História vai tecendo na vida das personagens, isto, na vida dos humanos.

Palavras-chave:

Maria Velho da Costa, História, personagens

Abstract:

Maria Velho da Costa's literary work offers us a vision, brought together by the figurations of the characters and the complex webs elaborated between them, of a historical path that dispenses any form of tranquility or peace. The restlessness that inhabits it isn't only subjectively personal - reflecting, as well, the various surprises that History weaves in the lives of the characters, that is, in the lives of all humans.

Keywords:

Maria Velho da Costa, History, characters

Maria Velho da Costa pertence à família de escritores que sabem que, debaixo da crosta aparentemente sólida e estável do mundo, vibram forças que sacodem as vidas dos homens. Alguns destes apercebem-se delas. Não serão certamente os mais felizes, mas são entretanto aqueles que preferencialmente moram na ficção desta escritora e cujas vozes nos vão falando, historicamente inscritas. Este é um ponto que importa sublinhar desde o início: de uma forma ou de outra, todas as obras de Maria Velho da Costa ressoam num mundo histórico que se dá a ver, e fazem-no ressoar através de perturbações que são simultaneamente ficcionais e mais amplamente humanas. Assim, importa reconhecer para já que os contextos reconhecíveis nas obras (do século XIX de Madame, criando o diálogo entre as personagens femininas de Eça e Machado de Assis, até ao início do século XXI, com "o meio" literário e cultural que se agita e é percorrido em $O$ Livro do Meio, passando pela Revolução dos Cravos ou a invasão de Timor) fazem parte integrante daquilo que é escrito. Mais do que cenários, são elementos centrais da obra. A história é, assim, um elemento-chave da efabulação de Maria Velho da Costa, vista através dos modos diferenciados como se figura nas vidas dos humanos. Crianças, mulheres, mestiços, famílias, noites/madrugadas, revoluções e invasões, infâncias e sacrifícios, 
Cadernos de Literatura Comparada

Colidir na História

imigrantes - todos eles conhecerão um instante de explosão na história, que a ficção inscreve e que a obra de Maria Velho da Costa nos vai fazendo ler.

\section{"Mundos clausos"}

O mundo que se agita nesta obra, como vimos extensa e multiforme, é um mundo dilacerado por movimentos de pendor aparentemente contrário, que definem as relações das personagens fundamentalmente como perturbadoras e instáveis, várias vezes mesmo de uma ambiguidade que se caracteriza como irresolúvel: dilacerado entre o que converge para um centro por vezes obscuro de onde tudo parece dimanar (como Timor, em Missa in Albis, ou o lado nocturno da cidade, em Irene ou O Contrato Social) e o que manifesta, de modo igualmente intenso, uma força centrífuga e divergente; entre o que parece ser fechado e o que surge animado de movimentos em direcção a aberturas e cruzamentos o mais das vezes inopinados e imprevisíveis; entre algumas das esperanças que escrevem as várias "madrugadas" (para citar o título de um dos capítulos de Lucialima) que as cenas pessoais e sociais julgam poder antever (como o Sul e o Sol desejados por Myra, no romance com o mesmo título) e as também não menos evidentes desesperanças e os refluxos que esses movimentos patenteiam. Serão algumas destas agitações que, de forma necessariamente breve, seguirei no universo efabulatório de Maria Velho da Costa, embora acrescente desde já que elas se encontram também no centro dessa obra inusual que é $O$ Livro do Meio, livro de memórias e reflexão pessoal em que, como vimos, Maria Velho da Costa e Armando Silva Carvalho colaboram, voltando ao passado de ambos e interrogando o dia do presente e as suas personagens, por vezes cruamente dissecadas.

Uma das formas que essa agitação pode tomar é a que poderá aqui ser entendida sob a designação genérica de clausura, e que atrás brevemente descrevi nos seus traços mais gerais - e gostaria desde já de apontar que a coloco na esteira de algumas das tradições romanescas mais fortes da Literatura Portuguesa, nomeadamente de Almeida Garrett e Camilo Castelo Branco (ambos autores sobre quem Maria Velho da Costa também aliás trabalhou, e espero deixar claro que tal não terá acontecido por acaso). Na realidade, encontramo-nos de certa forma sempre perante "mundos clausos", famílias (também elas mutantes, mas não é a própria família tradicional que está em mutação?), núcleos triádicos como o composto pelo universo concentracionário de Irene, Lia e Raquel em Irene..., ou aquela outra tríade composta pelas personagens femininas de Elisa, Mary e Elvira, encontrada na "Terça Casa" do romance Casas Pardas. Trata-se de algum modo do reconhecimento de mistérios normalmente nunca de facto completamente desvendados, como o que caracteriza, paradigmaticamente, Missa in Albis, em torno da personagem Sara, ou aqueloutro que junta, no romance Myra, a personagem do mesmo nome, imigrante do Leste em Portugal, e o seu cão de combate, Rambo, na peregrinação em direcção ao Sul que a ambos une. Assim, estes mundos clausos são, já não os lugares estáveis que uma certa ideologia neles tinha implantado mas, pelo contrário, o lugar da manifestação mais intensa de dúvidas e incertezas, rede de vozes e versões contraditórias, diálogo 
feito pela justaposição de aparentes monólogos que se somam mas também colidem entre si.

Chegamos assim a um dos termos que gostaria de propor como centrais para a obra de Maria Velho da Costa: o termo colisão, que me parece poder corresponder ao modo simultaneamente plural e agitado pelo qual a forma "romance" é agarrada e praticada. Poderíamos dizer o mesmo, aliás, de outras formas utilizadas por Maria Velho da Costa, com particular destaque para o conto ( 0 Amante do Crato ou Dores) e para o teatro (Madame). Trata-se, em todas elas, de assistir ao encontro e choque perturbador de algumas cenas de vida, tocadas pelo desencanto do passado (a infância, como em 0 Livro do Meio) ou do futuro (negado, como em Irene ou 0 Contrato Social, ou em Myra). Trata-se pois de uma colisão como quando se diz, em química, que as partículas colidem entre si para simultaneamente se destruirem e criarem algo de novo - mas também de obscuro, porque inquieto. E para ela a imagem talvez mais intensa seja a da "Casa Branca" que no romance Myra por alguns breves instantes faz viver em comunidade um grupo de indivíduos das mais diferentes nacionalidades, que a história fez aportar ao Alentejo, em Portugal: uma comunidade cosmopolita, desse novo cosmopolitismo a que um crítico brasileiro, Silviano Santiago, chamou "o cosmopolitismo do pobre".

Esta dimensão caótica do que de novo surge parece-me ser o lado pelo qual a efabulação é proposta, por Maria Velho da Costa, como simultaneamente realista e visionária. É este um ponto que gostaria em especial de sublinhar: no espaço de uma ficção que diríamos pertencer grosso modo ao universo realista (e, como vimos, fortemente histórico), irrompem de modos diversos balbuciamentos do imaginário, do inconsciente, da fantasia ou do fantasma. Por isso, personagens como Irene e Orlando, ou Elvira e Mary, Myra e Rambo, são faces diferentes da mesma história que se escreve, encontram-se num mesmo momento vindo de trajectórias diferentes, colidem com diversos passados e desejos de futuro, e desses encontros nascem vozes que, sendo realistas, assumem por vezes contornos fantásticos, nomeadamente pelo intenso trabalho que em torno do discurso pessoal e especificamente interior Maria Velho da Costa realiza. Essa experiência de des-realização da linguagem, deixando-a permeável às forças contraditórias e inexplicáveis do inconsciente, atravessa muito especialmente livros como Casas Pardas e Irene..., manifestando neles a forma como a matéria verbal ganha densidade e se altera, no cruzamento de vozes diferentes, naquilo que um verdadeiro diálogo é: não o encontro do semelhante, mas a exposição do dissonante. A polifonia que mora, como pulsão e realidade, na obra desta escritora é o núcleo do que faz cruzar mundos diferentes a que as personagens pertencem.

Por outro lado, de tudo isto decorre um outro aspecto que gostaria de sublinhar: o carácter singular e até várias vezes paradigmático (isto é, exemplar e simultaneamente "depurado") da fábula construída dentro do universo narrativo. No entanto, e simultaneamente, porque é paradigmática, essa fábula encontra de forma imediata modos de conivência com o carácter comum que nela reconhecemos também - e que faz com que nela sejam reconhecíveis uma estratégia social e uma imersão comunitária. Em Das Áfricas, Maria Velho da Costa sublinha, em determinado momento, o duplo sentido do adjectivo "comum", como por um lado o que se enraíza no quotidiano e dele parte, e por outro como o que pertence a uma comunidade. 
Esta observação poderia dizer-se válida, precisamente, para o conjunto da sua obra. Aquilo que acontece é duplamente "comum", em ambos os sentidos que Maria Velho da Costa refere.

Entretanto, se as fábulas são sobre pessoas individuais, ditas personagens, e não sobre alegorias desencarnadas, o certo é que uma determinada forma de mediação alegórica, ao modo do que Baudelaire inaugurou para a modernidade, me parece igualmente visível em toda a ficção de Maria Velho da Costa. É por essa mediação alegórica que tais fábulas pessoais ressoam, em círculos concêntricos que se expandem, em direcção a procedimentos e problemas sociais: problemas de classe, problemas políticos, problemas de discriminação, sobretudo problemas de desamparo e de vulnerabilidade - reconhecimento de margens e lugares periféricos como o da criança na sociedade pensada pelos adultos (Lucialima); da imigrante que julgou poder acreditar no futuro (Myra); do negro ou mulato num mundo de brancos (Irene...); da mulher nas redes e vozes masculinas (Maina Mendes; Novas Cartas Portuguesas; Casas Pardas); da demência (Irene...). O sujeito vulnerável que atravessa a obra desta autora, e que tão diversamente se configura nela, arrasta-se na História, dela participa, nela tem um papel manifesto, como voz pessoal dessa grande voz social de que todos participamos. E no entanto essa voz pessoal é uma espécie de combate na História, porque no palco dos grandes acontecimentos sociais que se agitam (a Revolução de 1974, a invasão de Timor, a descoberta de Portugal como país de imigração infeliz) as personagens que falam dizem, também, a sua própria história pessoal, de incompreensão e abandono.

\section{"Contratos sociais"}

Com este gostaria de relacionar ainda um outro aspecto que, de ordem mais discursiva, me parece entretanto funcionar precisamente como uma formulação diferente para a mesma questão (a da colisão entre o pessoal e o social). Trata-se do explícito uso, recorrente e incorporado, da citação de vozes e discursos-outros ao discurso inevitavelmente próprio - e inevitavelmente não apenas porque qualquer um o é, mas porque a experimentação discursiva de Maria Velho da Costa se escreve justamente nesse lugar em que a pessoalidade corporal do discurso é não só praticada como até mesmo reclamada. A linguagem surge assim como lugar de experimentação da também ela colisão entre as vozes das várias personagens (por exemplo, Missa in Albis); entre várias línguas, em particular os crioulos (com particular destaque para Missa in Albis e Irene...); entre vários autores (apenas de forma indicativa: Camões, Camilo, Virginia Woolf, Shakespeare, Gil Vicente, Fernão Lopes, Irene Lisboa, Rousseau, Eça, Machado de Assis, A Bíblia); entre vários grupos sociais e regionais (uma certa marginalidade transgressora urbana e nocturna, os writers, em Irene...); entre estatutos e condições de vida (Capitu e Maria Eduarda, em Madame); ou mesmo entre a possibilidade de usar ou não a linguagem e o silêncio, de ir alterando nomes, sotaques e nacionalidades para dar conta de uma linguagem que, em última análise, nunca é a sua (Myra).

$\mathrm{O}$ acto possível de reconciliação, a existir, é, então também, um acto que nasce desta 
mesma colisão entre o que surge de forma diferenciada, e que, longe de a anular, a integra e incorpora. Tal implica que as relações descritas dificilmente se podem incluir numa estrutura de tipo alternativo ou disjuntivo, em que se tratasse de escolher entre o modo do encontro e o modo da ruptura: em cada momento, há encontros e rupturas que sucedem, uns levando a outros. A relação entre Orlando e Irene pode ser aqui evocada como paradigmática, a este respeito: entre eles ocorre uma reconciliação social que nasce da improvável coalescência entre os que se manifestam como diferentes. É por isso que a sombra de um Camilo, que de outros pontos de vista poderia parecer estar longe deste universo (e já vimos que dele está muito perto), inevitavelmente se projecta sobre a prática romanesca de Maria Velho da Costa. E por isso ainda é que a arquitectura rigorosa dos romances desta escritora é muito naturalmente mais do que um mero processo técnico de construção discursiva: antes uma forma de manifestar, através do movimento que a arquitectura ergue (e faz ruir), o carácter exemplarmente plural que as várias personagens e as várias histórias assumem no complexo tecido de relações que entre si estabelecem.

Trata-se então, e para utilizar de forma também paradigmática o título do romance de Maria Velho da Costa, de "contratos sociais", porque os há sempre, embora inevitavelmente ligados aqui a uma dimensão de solidão, morte e dor (o volume de contos Dores é bem claro a este respeito), mais do que a um entendimento consensual e tácito que faça radicar a sobrevivência e a vida pessoais numa experiência social regulada e estabilizável, "à la Rousseau". Deste ponto de vista, é do reverso da esperança iluminista que aqui se trata - embora essa esperança nela sempre resida, como lugar que brilha e dá fundura mesmo às dores e às desesperanças do mundo: o que encontra a sua imagem simbólica na "madrugada" que, ao abrir o romance Lucialima, proclama que as desestabilizações e agitações do mundo são precisamente o lugar por onde a escrita e a linguagem podem aproximar-se do buraco negro de sentido em que o mundo contemporâneo parece tantas vezes ter-se transformado.

Também aqui age o mundo clauso que a dimensão paradigmática posteriormente abrirá: o contrato social é no romance de Maria Velho da Costa apanhado por dentro, dentro da estrutura familiar e grupal atravessada e corroída por percursos e poderes e hierarquias de regras e sofrimento. E, por isso, o contrato social é também aquele que, ao mesmo tempo, inevitavelmente liga e aproxima as pessoas, por um lado e, por outro, ao cruzá-las, as faz desabar umas contra as outras, Raquel contra Irene, Orlando contra a mãe, Ezequiel contra Capitu. A forma romanesca e mais amplamente ficcional torna-se, de algum modo, naquilo que o romance Irene... designa (p. 90) como "a anestesia hiperlúcida das catástrofes", se bem que em círculo como vimos expandido: verdadeiramente, o encontro será o que ocorre entre quem se desconhece, o par emblemático Orlando e Irene de Irene..., ou aquele outro protagonizado por Maria Eduarda/Eunice e Capitu/Eva, de Madame, ou ainda a improvável doçura e crueldade que unem Myra e Rambo (para usar os casos mais recentes). Todos eles implicam sempre, todavia, a verdadeira dimensão passional que envolve e concentra e sugere vida, sofrimento e morte. Mas para isso é preciso que outros encontros aconteçam, Raquel e Orlando por exemplo, ou mesmo os virtuais Eça e Machado, Maria Velho da Costa e Shakespeare. A 
Cadernos de Literatura Comparada

Colidir na História

dimensão ficcional parece então poder coincidir com as histórias múltiplas e divergentes pelas quais o destino armadilha o humano, incendiando-o com as malhas da paixão e do desejo mas também do caos desordenado e das catástrofes que acontecem: Timor ou o sismo de 1969, que ecoam. 